\title{
Carbon storage and mineralization potential of soils under major plantation crops in the Western Ghats region of Kerala, India
}

\author{
Phebe Joseph*, M. D. Jessy and Mahesh Mohan ${ }^{1}$ \\ Rubber Research Institute of India, Kottayam-686 009, Kerala, India \\ ${ }^{1}$ Mahatma Gandhi University, Kottayam-686 560, Kerala, India \\ (Manuscript Received: 22-02-2020, Revised: 22-10-2020, Accepted: 28-10-2020)
}

Keywords: Carbon mineralisation, plantation crops, soil carbon, water stable aggregates

Accurate estimation of soil organic carbon (SOC) and the evaluation of factors influencing its mineralization under different land use systems have become vital for recuperating soil quality, maximising productivity and alleviating the effects of elevated atmospheric $\mathrm{CO}_{2}$ on global warming. As the major component of soil organic matter (SOM), SOC plays a crucial role in determining whether soil serves as either sinks or sources of carbon (C) in the global C cycle. Roughly 55 to 60 per cent of the SOM is SOC and it encompasses all organic components and fractions in the soil, including plant and animal residues in different phases of disintegration, root and microbial exudates and highly stable organic materials (Schwendenmann et al., 2007). The quantity of SOC stored in soil is a function of the net balance between the amount of $\mathrm{C}$ depositing in the soil and the rate of mineralization (Post and Kwon, 2000), that varied with type of soil, vegetation and management practices.

Changing patterns of land use systems and agricultural practices significantly influenced mineralization of SOC and contributed 20 per cent increase in atmospheric $\mathrm{CO}_{2}$ concentration (Rahman, 2013). Tree based land use systems are considered as one of the vital options for reducing $\mathrm{CO}_{2}$ emission as well as enriching $\mathrm{C}$ sink. Zomer et al. (2016) reported that the $\mathrm{C}$ storage potential of world's agricultural land was $45.3 \mathrm{PgC}$ of which more than 75 per cent was contributed by tree cover and further increase of 3.7 per cent tree cover during the period 2000 to 2010 resulted in an increase of more than $2 \mathrm{PgC}$ of biomass $\mathrm{C}$.

The perennial plantation agriculture is the major tree based land use system in Kerala, the south western coastal state of India. Rubber, tea, coffee and cardamom are the major plantation crops of the region and these plantations were established initially in forest cleared lands rich in organic matter and plant nutrients, and later on, cultivation extended to marginal lands. Different agroforestry systems have different agro-climatic and soil requirements, net primary production, root distribution, litter quality and quantity, and these factors affect the SOC dynamics of the system. To develop a suitable soil management strategy for a sustainable agricultural production system, the use of appropriate indicators that are sensitive enough to reflect the changes in SOC quality and quantity is very important (Philip and Abraham, 2016). The quantities of labile and recalcitrant fractions of SOC are sensitive to land management practices. The impacts of alteration of land use patterns and agricultural operations occur much more rapidly in the labile SOC fraction, which is considered to be the fine indicator of soil quality (Hoyle et al., 2006). Soil organic carbon is physically protected by soil aggregates and is an effective strategy to mitigate global climate change. Soil aggregate stability is considered as a measure of OC content, microbial activity and nutrient cycling in soil. Xiang et al. (2015) suggested that waterstable aggregation is an

*Corresponding Author: phebejoseph123@gmail.com 
important process to assess soil aggregation and bring forth valuable information on soil aggregate stability. Waterstable aggregation is composed of macro aggregates $(>250 \mu \mathrm{m})$ and micro aggregates $(<250 \mu \mathrm{m})$ of which macro aggregation is very sensitive to changing patterns of land use systems and agricultural operations and in micro aggregation changes is much less (Angers, 1992; Bernard, 1996).

A better understanding of the $\mathrm{C}$ storage potential and $\mathrm{C}$ mineralization in soils of different plantation sectors is essential for developing the best management practices and prediction tools for enhancing $\mathrm{C}$ storage, thereby increasing agricultural sustainability of the systems. Keeping this in view, a study was conducted to determine the $C$ sequestration potential, $\mathrm{C}$ mineralization and rate of soil respiration in major plantation crops of Kerala.

The experimental area was located in the predominant plantation sectors viz., rubber, coffee, cardamom and tea, in the Western Ghats region of Kerala, South India. Coffee, tea and cardamom plantations were adjacent to each other and were situated in the AVT tea plantations, Vandiperiyar, Idukki $\left(9^{\circ} 34^{\prime} 7.19^{\prime \prime} \mathrm{N}\right.$ latitude and $77^{\circ} 05^{\prime} 15.60^{\prime \prime} \mathrm{E}$ longitudes and altitude $836 \mathrm{~m}$ above MSL). The rubber plantation was located on the border of Idukki district at Mundakayam, Kottayam lies between $9^{\circ} 30^{\prime} \mathrm{N}$ latitude and $76^{\circ} 53^{\prime} \mathrm{E}$ longitude and altitude $78 \mathrm{~m}$ above MSL. The study areas come under humid tropical climatic regime with annual average temperature of $23.2{ }^{\circ} \mathrm{C}$ and $27.5^{\circ} \mathrm{C}$ and rainfall of $2045 \mathrm{~mm}$ and $2556 \mathrm{~mm}$ in Vandiperiyar and Mundakayam, respectively (Envis Centre Kerala, 2018).

The vegetation type and agricultural practices are important for the production and diffusion of $\mathrm{CO}_{2}$ to soil surface. The rubber (Hevea brasiliensis) plantation was 13 years old and in the $3^{\text {rd }}$ cycle of cultivation. The leguminous cover crop, Mucuna bracteata was planted in the inter rows of rubber during the initial years. The planting density was 450 plants ha ${ }^{-1}$ and all cultural operations were done as per the recommendation of Rubber Board, India. In mature phase fertilizer@30:30:30 kg $\mathrm{N}: \mathrm{P}_{2} \mathrm{O}_{5}: \mathrm{K}_{2} \mathrm{O}$ ha $^{-1}$ year $^{-1}$ was applied in two splits. The cardamom (Elletteria cardamomum) plantation was established under rain fed conditions and fast growing shade trees were planted in the system for shade regulation. The age of the plantation was eight years and the planting density was 2000 plants ha ${ }^{-1}$. The recommended dose of manures and fertilizers was $5 \mathrm{~kg}$ plant $^{-1}$ and 75:75:150 kg N: $\mathrm{P}_{2} \mathrm{O}_{5}: \mathrm{K}_{2} \mathrm{O}$ ha $^{-1}$ year ${ }^{-1}$, respectively. To reduce soil acidity, agricultural lime@1 kg plant ${ }^{-1}$ year $^{-1}$ was applied before fertilizer application. All agro management practices were done as per the recommendation of Spices Board, India. In coffee plantation (Coffea canephora syn. Coffea robusta) the planting density was 1600 plants ha-1 and age of the plantation was 30 years. To provide shade for coffee plants different species of shade trees were established and maintained. Fertilizers at the rate of 120:90:120 kg $\mathrm{N}: \mathrm{P}_{2} \mathrm{O}_{5}: \mathrm{K}_{2} \mathrm{O}$ ha $^{-1}$ year $^{-1}$ was applied in three splits. Around $3 \mathrm{tha}^{-1}$ of agricultural lime was applied once in three years and general cultural operations were done as per the recommendation of Coffee Board, India. Tea (Camellia sinensis (L.) O. Kuntze) is an intensively managed perennial cash crop and in the experiment area it was planted in a double hedge system with a planting density of $13200 \mathrm{ha}^{-1}$. For shade regulation, silver oak (Grevillea robusta) was established and maintained from the initial years onwards. Fertilizers @ 300:100:300 kg N: $\mathrm{P}_{2} \mathrm{O}_{5}: \mathrm{K}_{2} \mathrm{O}$ ha $^{-1}$ year $^{-1}$ was applied in 6 splits and for reducing acidity dolomite $1 \mathrm{t} \mathrm{ha}^{-1}$ was applied yearly. All agro management practices were followed as per the recommendation of Tea Board.

From each plantation of one hectare area, 10 soil samples were collected randomly (a minimum of five soil samples were used to make up one composite sample) from a depth of 0-30 $\mathrm{cm}$ for physical and chemical analysis. Total carbon (TC) and nitrogen (TN) determination was done with an automated CHNS analyser (CHNS LECO). Automated TOC analyser was used to estimate SOC and inorganic carbon (IOC). The oxidized SOC fractionations (F1, F2, F3 and F4) were determined by wet oxidation method suggested by Chan et al. (2001). The F1 and F2 fractions were composed of more easily oxidizable C (Labile form) while F3 and $\mathrm{F} 4$ fractions were made up of more recalcitrant organic $\mathrm{C}$ compounds. Lability index (LI), the ratio of carbon labile (CL) to the carbon nonlabile fraction of the soil was tabulated as per Blair et al. (1995).

The soil bulk density (BD) was measured by core sampling method described by Black (1965). 
The SOC stock was estimated as per the following equation:

Soil organic carbon stock $\left(\mathrm{Mg} \mathrm{ha}^{-1}\right)=\mathrm{SOC} \times \mathrm{BD} \times \mathrm{T}$

where, SOC is the soil organic carbon content in per cent, BD is the soil bulk density in $\mathrm{g} \mathrm{m}^{-3}$ and $\mathrm{T}$ is the thickness of the soil layer in $\mathrm{cm}$.

Water stable aggregates (WSA) fractionations were determined using a modified Yoder type apparatus (Wet sieving method-Yoder, 1936). The soil samples were subjected to physical fractionation and obtained three aggregate size classes (250 - 2000 $\mu \mathrm{m}, 53-250 \mu \mathrm{m}$ and $<53 \mu \mathrm{m})$. A sample of $100 \mathrm{~g}$ air dried and $2 \mathrm{~mm}$ sieved soil was placed on the top of a column of nested sieves $(0.25$ and 0.053 $\mathrm{mm}$ opening), with the largest mesh opening on the top. Prior to sieving the soil under water, the soil was submerged with deionized water for $10 \mathrm{~min}$ at room temperature to remove the air trapped inside soil pores. The soil samples were sieved manually by oscillating the nested sieves within a column of water for $5 \mathrm{~min}$. The materials retained on each sieve were transferred into an aluminium container, oven dried at $60^{\circ} \mathrm{C}$ for 24 hours and weighed. Calculated the amount of WSA for every aggregate size class and analyzed $\mathrm{C}$ content of each fraction. The aggregate stability indices, mean weight diameter (MWD) and the geometric mean diameter (GMD) were calculated by the formula:

$$
\begin{aligned}
& M W D=\sum_{i=1}^{n}\left(X_{i} W_{i}\right) \\
& G M D=\exp \left[\sum_{i=1}^{n}\left(W_{i} \operatorname{In} X_{i}\right)\right]
\end{aligned}
$$

Where, $X_{i}$ is the average diameter of each aggregate size fraction $(\mathrm{mm})$ and $W_{i}$ is the weight ratio of the remained aggregates on the sieve (Mazurak, 1950).

Carbon mineralization potential of different plantation systems was assessed by conducting a laboratory incubation study at constant room temperature. Ten grams of soil was wetted with deionized water to 50 per cent field capacity and placed in airtight jar containing vials with $20 \mathrm{~mL}$ of water to maintain high humidity and $10 \mathrm{~mL}$ of $1 \mathrm{M}$
$\mathrm{NaOH}$ for trapping $\mathrm{CO}_{2}$ released from soil. Incubated the samples at $25{ }^{\circ} \mathrm{C}$ for 40 days and replicated 5 times. The vials with $\mathrm{NaOH}$, were taken out at regular intervals of $5,10,15,20,25,30,35$ and 40 days from the initial day of incubation and titrated with $0.5 \mathrm{M} \mathrm{HCl}$ after addition of one $\mathrm{mL}$ of saturated $\mathrm{BaCl}_{2}$, for quantifying evolved $\mathrm{CO}_{2}$ (Lakaria et al., 2012).

All data were tested with single factor analysis of variance (ANOVA) by using the software SPSS (SPSS Inc,USA) and statistical significant differences were assessed at the $\mathrm{p}<0.05$ level.

The data on carbon pools in the top $30 \mathrm{~cm}$ soil depth under the different systems are given in Table 1. The amount of TC, OC and IOC components of soils varied with plantation systems. The highest per cent of these parameters were observed in coffee soil compared to all other systems and the lowest in rubber. Coffee system had 10 per cent more of TC and $\mathrm{OC}$ than the cardamom and tea system and more than twice that of rubber. The storage potential of $\mathrm{TC}$ and $\mathrm{OC}$ in different land use systems is highly dependent on the site and the different features of the systems including altitude, climatic patterns, soil characteristics, crops cultivated addition of organic matter inputs and agro-management practices followed. In coffee system, the biomass addition through coffee and shade trees was approximately 17.4 $\mathrm{MT} \mathrm{ha}^{-1} \mathrm{yr}^{-1}$ (Arellano et al., 2004) and was several fold higher than that of cardamom (5.5 MT $\left.\mathrm{ha}^{-1} \mathrm{yr}^{-1}\right)$ (Krishnakumar and Potty, 2003), tea and rubber system (6 MT ha-1 $\mathrm{yr}^{-1}$ ) (Krishnakumar and Potty,1992). Vieira et al. (2011) observed a direct relationship of both TC and OC with altitude due to relatively lower soil and air temperature at the higher altitudes. Generally, coffee, tea and cardamom plants are grown in higher altitude regions whereas rubber is grown in lower altitudes below $400 \mathrm{~m}$ above MSL. The cooler climate and relatively higher soil moisture in higher elevations slow down the OM decomposition by soil microbes, thus facilitating accumulation of denser OM in soil. This condition will restrict the emission of $\mathrm{CO}_{2}$ from the soil and contribute to higher TC and OC in coffee, tea and cardamom soils. The high temperature and low soil moisture in lower elevations lead to higher mineralization of SOC (Ping et al., 2015) and thereby the lowest soil carbon pools in the rubber 
Table 1. Carbon pools and bulk density (BD) of soils under different plantation crops

\begin{tabular}{|c|c|c|c|c|c|}
\hline Plantation crop & TC $\left(\mathrm{t} \mathrm{ha}^{-1}\right)$ & OC $\left(\mathrm{t} \mathrm{ha}^{-1}\right)$ & $\operatorname{IOC}\left(\mathrm{t} \mathrm{ha}^{-1}\right)$ & SOC stock (t ha-1) & BD $\left(\mathrm{g} \mathrm{cm}^{-3}\right)$ \\
\hline Rubber & 43.0 & 40.4 & 2.6 & 80.0 & 1.32 \\
\hline Coffee & 107.2 & 99.7 & 7.5 & 172.0 & 1.15 \\
\hline Tea & 90.6 & 85.2 & 5.4 & 152.0 & 1.24 \\
\hline Cardamom & 95.6 & 90.8 & 4.8 & 152.6 & 1.12 \\
\hline $\mathrm{SE}$ & 2.4 & 2.3 & 0.2 & 1.8 & 0.019 \\
\hline $\mathrm{CD}(\mathrm{P}=0.05)$ & 3.2 & 3.1 & 0.3 & 2.1 & 0.03 \\
\hline
\end{tabular}

system. In coffee system, the highest litter input and low mineralization rate might result in the highest $\mathrm{TC}$ and $\mathrm{OC}$ in soil.

The IOC content of different cropping systems varied considerably from $2.58 \mathrm{tha}^{-1}$ to $7.5 \mathrm{tha}^{-1}$ and follows the same trend in TC and $\mathrm{OC}$ as the highest per cent in coffee and the lowest in rubber system. Shi et al. (2017) found a strong positive correlation between OC and IOC. In the coffee system, IOC accumulation might be enhanced by an increase of OC.

Significant difference in BD was observed among different systems and ranged between 1.12$1.32 \mathrm{~g} \mathrm{~cm}^{-3}$ in the top $0-30 \mathrm{~cm}$ soil (Table 1). Bulk density linearly affects SOC stock because it is the product of soil OC per cent and BD (Walter et al., 2016). The smallest value of $B D$ recorded in cardamom $\left(1.12 \mathrm{~g} \mathrm{~cm}^{-3}\right)$ and coffee system $(1.15 \mathrm{~g}$ $\mathrm{cm}^{-3}$ ) could be related to higher SOC storage of the system. On the other hand, the highest BD in rubber system $\left(1.32 \mathrm{~g} \mathrm{~cm}^{-3}\right)$ might be owing to the lower soil aggregate stability resulting from the high rate of OM mineralization in lower altitude. This in turn affects porosity and moisture retention capacity of the soils. The critical value of soil BD for plant growth is $1.6 \mathrm{~g} \mathrm{~cm}^{-3}$ at which the root penetration in soil is severely restricted (McKenzie et al., 2004). This indicated that among the plantation systems even though BD varied, the soils were not excessively compacted and penetration of roots in soils was not restricted. The variation in OC content and BD of systems contributed different SOC stock.

The SOC stock for the upper $30 \mathrm{~cm}$ soil layer of different plantation systems is given in Table 1 . Among the systems, coffee system $\left(171.96 \mathrm{t} \mathrm{ha}^{-1}\right)$ had the highest SOC stock followed by cardamom $\left(152.6 \mathrm{t} \mathrm{ha}^{-1}\right)$ and tea $\left(152.01 \mathrm{t} \mathrm{ha}^{-1}\right)$ and the lowest was in rubber system $\left(80.03 \mathrm{t} \mathrm{ha}^{-1}\right)$. The coffee system had around 13 per cent more SOC stock than cardamom and tea systems and per cent more SOC stock than that of rubber. The values of SOC stock varied in accordance with the concentration of OC and BD of soil. The SOC stock of a system is also determined by topography, climate, hydrology, type of vegetation and the soil (Gupta and Rao, 1994).

Fractions of organic carbon extracted from soils of different systems were significantly different (Table 2). The value of active carbon pool (labile organic carbon) in cardamom (30.96 $\left.\mathrm{t} \mathrm{ha}^{-1}\right)$, tea $\left(30.04 \mathrm{t} \mathrm{ha}^{-1}\right)$ and coffee $\left(30 \mathrm{t} \mathrm{ha}^{-1}\right)$ soils did not show any significant difference and the rubber soil recorded significantly lower value $\left(18 \mathrm{t} \mathrm{ha}^{-1}\right)$. However, when the per cent contribution of labile $\mathrm{C}$ fraction towards SOC was calculated it was observed that the contribution of labile carbon pool was the highest in rubber system (46\%) and that of coffee, cardamom and tea system was 32, 36 and 37 per cent, respectively. With respect to the passive carbon pool (recalcitrant), the highest value was recorded under the coffee system $\left(60.69 \mathrm{t} \mathrm{ha}^{-1}\right)$ which was significantly higher than all other systems and the lowest was recorded under rubber $\left(21 \mathrm{t} \mathrm{ha}^{-1}\right)$. The recalcitrant fraction of $\mathrm{C}$ in cardamom $\left(54.64 \mathrm{t} \mathrm{ha}^{-1}\right)$ and tea systems $\left(51 \mathrm{t} \mathrm{ha}^{-1}\right)$ were on par. The per cent contribution of recalcitrant $\mathrm{C}$ fraction towards SOC was in the order: coffee $(67 \%)>$ cardamom $(63 \%)>$ tea $(62 \%)$ and rubber (54\%). In all the systems, the recalcitrant $\mathrm{C}$ counterpart predominated over the labile carbon and for both counterparts maximum values were observed under the coffee system whereas the rubber system showed the lowest. The distribution of $\mathrm{C}$ fractions in soil had significant impact on alteration of physical, chemical and biological characteristics 
of soil which in turn affect atmospheric $\mathrm{CO}_{2}$ concentration. Hassink (1994) reported that the clay content of soil can affect the concentration of labile carbon pools and stabilization of recalcitrant carbon pools. In this study the clay content of different plantation systems varied in the order: coffee (35\%) $>$ cardamom $(34.5 \%)>$ tea $(32.5 \%)>$ rubber $(30 \%)$. The recalcitrant fraction of SOC can have more stability due to the strong clay mineral - SOM association (Brady and Weil, 2008). The constant supply of high amounts of litter contributed higher values of labile and recalcitrant $C$ fractions in coffee system. The high altitude with low temperature prevalent in the coffee ecosystem might result in slower rate of litter decomposition and the absence of soil disturbing intercultural operations also added higher $\mathrm{C}$ values (Haynes, 2005). The lowest values of both $\mathrm{C}$ fractions in the rubber system could be associated with high OC mineralization in lower elevation and low litter input compared to other systems.

The ratio between the labile $(\mathrm{CL})$ and the recalcitrant (CNL) fractions of SOC represents the carbon lability index (CL/CNL) of different systems and it ranged between 0.49 and 0.86 (Table 2.). Significant difference in carbon lability index was not observed among different systems indicated that the mobility of soil organic carbon pools in different systems was not varied.

The per cent distribution of various water stable aggregates under diverse plantation systems is shown in Table 3. In all the systems, the proportion of macro-aggregate $(2000-250 \mu \mathrm{m})$ fraction was more than the other two fractions. Significant difference in macro-aggregate was observed and the highest value was in rubber $(56.2 \%)$ and the lowest in coffee (44\%) system. In contrary to this the silt plus clay fraction $(<53 \mu \mathrm{m})$ was highest in the coffee system, which is on par with cardamom and tea and the lowest in rubber. The proportion of microaggregate fraction $(250-53 \mu \mathrm{m})$ ranged between $9.2-10.8$ per cent and was not significantly varied. Water-stable aggregation is considered as a suitable index of soil aggregate stability and their formation and the stability was directly related to SOC content. The high temperature prevailing in low elevated regions enhances decomposition rates of litter and SOC and there by high macro-aggregate fractions (Garten, 2011). This might be the reason for more macro-aggregates in the rubber system. The proportion of macro-aggregates in soil is used as a measure for evaluating the impact of soil management practices in land use systems. The macro-aggregates are not tightly bound as microaggregates and are erratic and susceptible to change in land use systems and agro management practices (Ashagrie et al., 2007; Huang et al., 2010). The proportion of silt plus clay fraction in soil is positively correlated with the silt clay mineralogy of the system. In any system, the quantity of SOC increases as the soil texture becomes finer (Tisdall and Oades, 1982) and the increasing concentration of the finer soil particles are associated with increased stabilization of SOC. Thus, in our experiment, the higher proportion and content of silt plus clay aggregate in the coffee, tea and cardamom system might enhance the retention of SOC in these systems.

Significant differences in mean weight diameter (MWD) and geometric mean weight diameter (GMD) were observed in various land use systems (Table 3). The highest MWD of 1.19 was registered

Table 2. Oxidisable carbon fractions and carbon lability index (LI) of soils under different plantation crops

\begin{tabular}{|c|c|c|c|c|}
\hline \multirow[t]{2}{*}{ Plantation crop } & \multicolumn{3}{|c|}{ Oxidized C (t ha $\left.{ }^{-1}\right)$} & \multirow{2}{*}{$\begin{array}{c}\text { Carbon lability } \\
\text { index } \\
(\mathrm{CL} / \mathrm{CNL})\end{array}$} \\
\hline & $\begin{array}{c}\text { Total organic carbon } \\
\left(\mathrm{t} \mathrm{ha}^{-1}\right)\end{array}$ & $\begin{array}{c}\text { Labile (CL) } \\
(\mathrm{F} 1+\mathrm{F} 2) \mathrm{t} \mathrm{ha}^{-1}\end{array}$ & $\begin{array}{c}\text { Recalcitrant } \\
(\mathrm{CNL})(\mathrm{F} 3+\mathrm{F} 4) \mathrm{t} \mathrm{ha}^{-1}\end{array}$ & \\
\hline Rubber & 39.0 & 18.0 & 21.0 & 0.86 \\
\hline Coffee & 90.7 & 30.0 & 60.7 & 0.49 \\
\hline Tea & 81.0 & 30.0 & 51.0 & 0.59 \\
\hline Cardamom & 85.6 & 31.0 & 54.6 & 0.57 \\
\hline$\overline{\mathrm{SE}}$ & 2.3 & 6.2 & 4.5 & 0.70 \\
\hline $\mathrm{CD}(\mathrm{P}=0.05)$ & 3.1 & 8.3 & 6.0 & NS \\
\hline
\end{tabular}


Table 3. Water stable aggregates and aggregate stability indices of soils under different plantation crops

\begin{tabular}{|c|c|c|c|c|c|}
\hline \multirow[t]{2}{*}{ Plantation crop } & \multicolumn{3}{|c|}{ Water stable aggregates $(\%)$} & \multicolumn{2}{|c|}{ Aggregate stability indices } \\
\hline & $\begin{array}{c}\text { Macroaggregates } \\
(2000-250 \mu \mathrm{m})\end{array}$ & $\begin{array}{c}\text { Microaggregates } \\
(250-53 \mu \mathrm{m}) \\
\end{array}$ & $\begin{array}{l}\text { Silt +Clay } \\
(<53 \mu \mathrm{m})\end{array}$ & MWD & GWD \\
\hline Rubber & 56.2 & 10.8 & 32.0 & 1.19 & 0.66 \\
\hline Coffee & 44.0 & 9.5 & 44.5 & 0.93 & 0.52 \\
\hline Tea & 50.0 & 10.0 & 39.0 & 1.07 & 0.52 \\
\hline Cardamom & 48.5 & 9.2 & 41.3 & 1.04 & 0.57 \\
\hline SE & 3.2 & 1.6 & 4.5 & 0.07 & 0.08 \\
\hline $\mathrm{CD}(\mathrm{P}=0.05)$ & 4.2 & NS & 6.1 & 0.09 & 0.11 \\
\hline
\end{tabular}

in the rubber system whereas the lowest value was in coffee (0.93). In cardamom and tea soils the values were on par. The GMD value recorded in different systems was in an increasing order of coffee, tea, cardamom with maximum in rubber. Both the MWD and GMD values were highest in rubber and the lowest in coffee soils. Liu et al. (2014) reported that MWD and GMD are the two critical indices of aggregate stability. The MWD indicated the proportion of macro-aggregates (Kihara et al., 2011) and GMD determines the size of the incessantly repeated aggregate size class (Filho et al., 2002). Higher concentration of macroaggregates resulted in high values of MWD and GMD in rubber system.

In all the plantation systems the TC content in WSA increased with decreasing size (Fig. 1). It was observed that among the systems significant difference in TC was noticed in macro and silt and clay fractions while the proportion of $\mathrm{TC}$ in the micro-aggregate fraction did not vary. The TC in the macro-aggregate of rubber was around 19

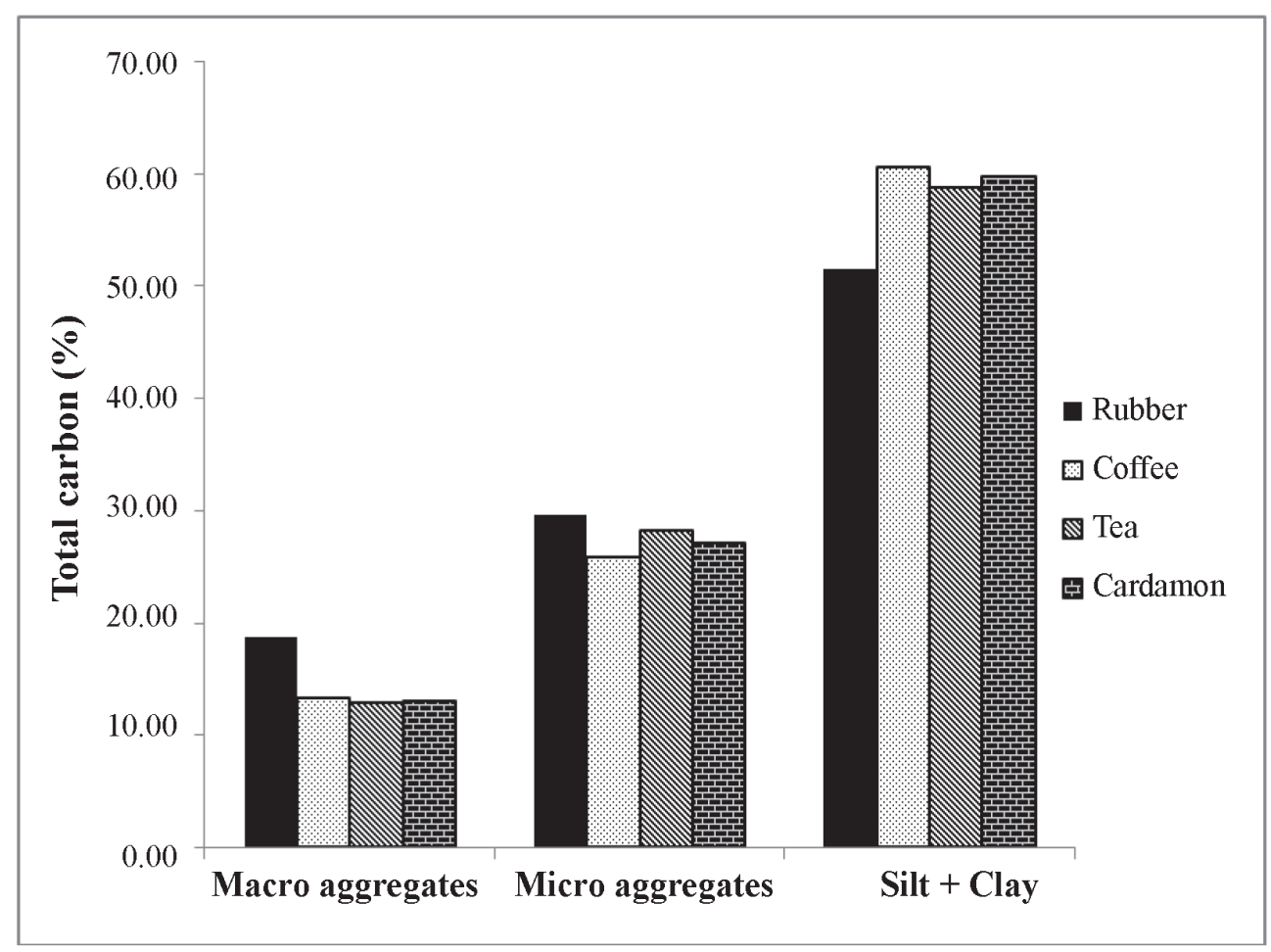

Fig. 1. Total carbon per cent in water stable aggregates of soils under different plantation crops 
per cent and was significantly higher than all other systems. In low altitude regions, the high decomposition of biomass and SOC might result in high macroaggregate turnover rates (Wang et al., 2010). The macro-aggregate mainly contains labile organic carbon that constitutes $\mathrm{C}$ source for soil microbes and are found around fresh OM. The carbon utilisation of soil microbes results in greater SOC turnover. In the rubber system the higher proportion of macro-aggregate fraction act as a transient $\mathrm{C}$ source for microbes, which add to the higher $\mathrm{C}$ content of macro-aggregates in the system (Messiga et al., 2011).

The $\mathrm{C}$ content in silt plus clay fraction is more stable than macro and micro fractions and it ranged from 51.6 to 61 per cent in different systems. In all the systems the silt plus clay fraction had the highest allocation of TC. It could be observed that the TC coupled with the silt plus clay fraction in coffee, cardamom and tea systems was 61, 60 and 59 per cent, respectively, whereas in rubber it was 51.6 per cent, which was significantly lower than all other systems. The collaboration between clay minerals and humic substances present in the OM offer more stable $\mathrm{C}$ in the silt and clay sized class (Brady and Weil, 2008).

The mineralization kinetics of soil carbon determined in different systems are given in Figure 2. Significant variation in mineralization of carbon was observed among different systems at different intervals. In all the systems during the initial 30 days, the rate of release of carbon was high and nearly stabilized thereafter. With incubation time, the quantity of carbon mineralized because of the loss of labile OC, which is easily disintegrated by soil microbes (Jia et al., 2015). A decreasing value for $\mathrm{C}$ mineralization was not attained within the time period of incubation. The cumulative $\mathrm{CO}_{2}$ evolution during the 40 days of incubation varied from 31 to $53 \mathrm{mg} \mathrm{CO}-\mathrm{C} 100 \mathrm{~g}^{-1}$ soil in different systems and the highest value was observed under the coffee system followed by cardamom, tea and rubber throughout the incubation period. The accumulation of OC is a function of the amount of biomass deposited to the system and the rate of its deterioration (Jenkinson, 1977). The large biomass addition and narrow $\mathrm{C}: \mathrm{N}$ ratio of coffee soil (Table. 4) favours the activity of microorganisms, results in higher cumulative $\mathrm{CO}_{2}$ evolution in the coffee

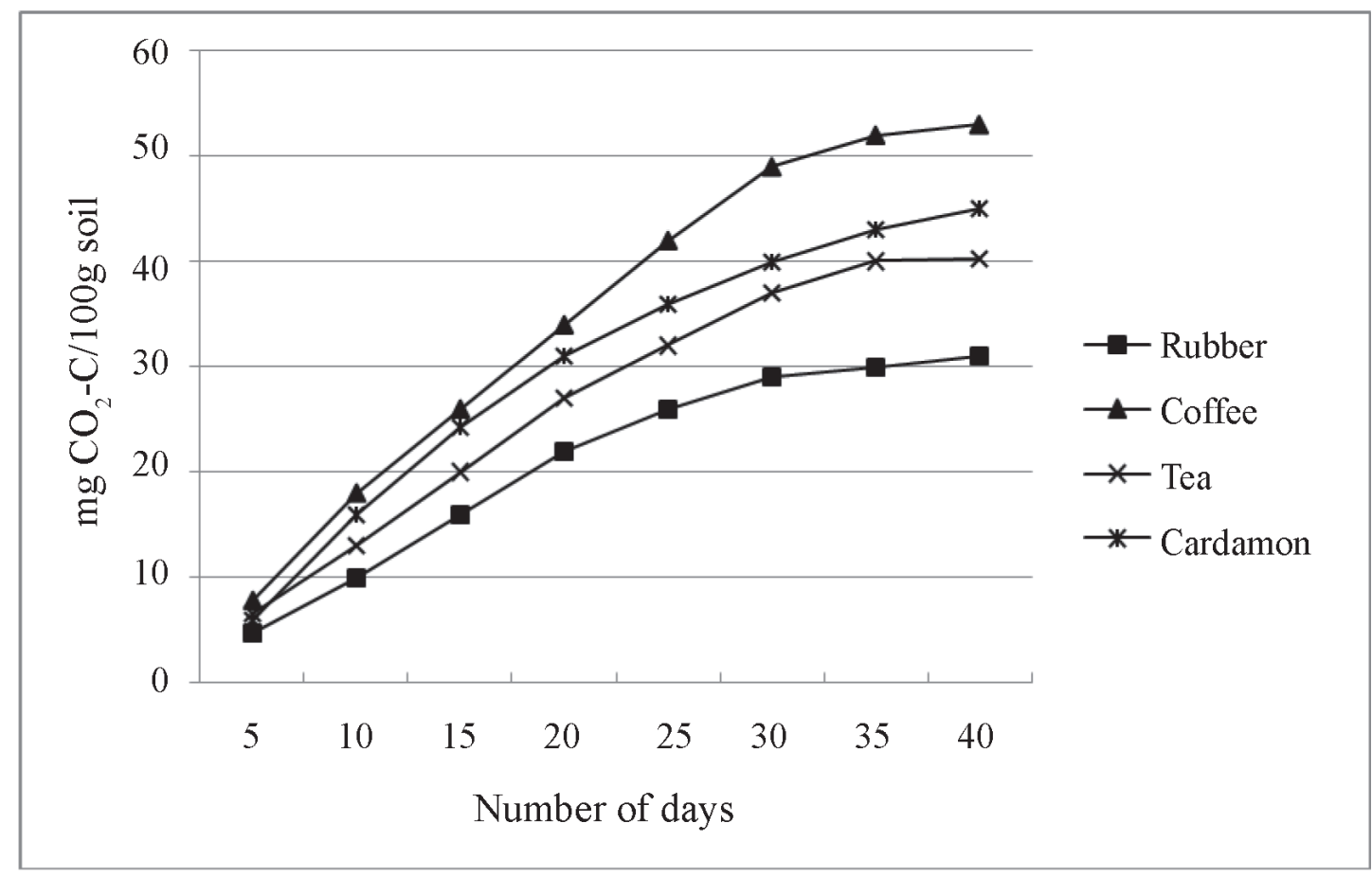

Fig. 2. Cumulative $\mathrm{CO}_{2}$ evolution in soils under different plantation crops 
Table 4. Total carbon mineralized and rate of mineralisation in soils under different plantation crops

\begin{tabular}{lcccc}
\hline Plantation crop & $\begin{array}{c}\text { Total carbon } \\
\left(\mathbf{g ~ k g}^{-1}\right)\end{array}$ & $\mathbf{C : N}$ & $\begin{array}{c}\text { TC mineralised } \\
\text { in 40 days } \\
\left(\mathbf{m g ~ C O} \mathbf{-}-\mathbf{C ~}^{-1} \mathbf{~ s o i l ~} \mathbf{~}\right)\end{array}$ & Mineralisation rate \\
\hline Rubber & 21.5 & 11.3 & 14.4 & 0.36 \\
Coffee & 53.6 & 11.7 & 9.9 & 0.25 \\
Tea & 45.3 & 13.3 & 9.6 & 0.24 \\
Cardamom & 46.8 & 15.1 & 9.6 & 0.24 \\
\hline SE & 1.1 & 0.7 & 0.2 & 0.00 \\
\hline CD $(\mathrm{P}=0.05)$ & 1.5 & 1.0 & 0.3 & 0.01 \\
\hline
\end{tabular}

system. The higher concentration of OC in coffee soil indicates higher nutrient supplying potential of coffee system.

In each plantation system the decaying capacity of OM was calculated by considering the quantity of $\mathrm{C}$ mineralized per unit weight of $\mathrm{C}$. The TC mineralized during the incubation period and the rate of $\mathrm{C}$ mineralization per day was remarkably greater in rubber system compared to all other systems which were on par (Table 4). Carbon mineralization in soil is an intricate bio-geochemical process and is closely associated with many direct and indirect components of which temperature is the most crucial parameter (Arevalo et al., 2012). Generally, mineralisation of carbon increases with temperature. The high temperature and lower soil moisture in low altitude regions have higher mineralization rate. Moreover, the variation in soil OC stability and selectivity of microbes for utilizing C also influences $\mathrm{C}$ mineralisation (Zhu et al., 2017). The climate and weather patterns prevalent in rubber plantation and the presence of large proportion of labile organic carbon pools contributed to a high mineralization rate in the rubber system. The low $\mathrm{C}$ mineralization rate in coffee, tea and cardamom indicate the high carbon sequestration potential of these systems compared to rubber.

The study showed that location, climate and agro management practices have marked effects on carbon storage and mineralization potential of different systems. The highest per cent of TC, OC and SOC stock was found in coffee plantation followed by cardamom, tea and the lowest in rubber. Altitude puts a great impact on soil carbon mineralisation in rubber plantation and the result suggests the important role of altitudinal gradient in $\mathrm{C}$ sequestration. The cumulative $\mathrm{CO}_{2}$ evolution and rate of $\mathrm{C}$ mineralisation in diverse systems indicated that all these plantations have vast potential for supplying plant nutrients and sequestering $\mathrm{C}$ in soils. The tree based land use systems play a vital position in the global $\mathrm{C}$ cycle and slight variations in SOC retention significantly affect the $\mathrm{CO}_{2}$ concentrations in the atmosphere. In future, more attention should be given to identify or develop more climate change compatible land management practices that enhance or maintain SOC in plantation sectors to mitigate climate change. The comprehensive data base of soil $\mathrm{C}$ reserves in different systems is also useful for making effective policies capable of implementing more sustainable agricultural operations that can enhance soil $\mathrm{C}$ storage and developing predictive models for $\mathrm{C}$ sequestration.

\section{References}

Angers, D.A. 1992. Changes in soil aggregation and organic carbon under corn and alfalfa. Soil Science Society of America Journal 56: 1244-1249.

Arellano, R., Paolini, J., Vásquez, L. and Mora, E. 2004. Litter production and decomposition in three coffee agroecosystems in Trujillo State, Venezuela. Revista Forestal Venezolana 48: 7-14.

Arevalo, C., Chang, S.X., Bhatti, J.S. and Sidders, D. 2012. Mineralization potential and temperature sensitivity of soil organic carbon under different land uses in the parkland region of Alberta, Canada. Soil Science Society of America Journal 76(1): 241-251.

Ashagrie, Y., Zech, W., Guggenberger, G. and Mamo, T. 2007. Soil aggregation, and total and particulate organic matter following conversion of native forests to continuous cultivation in Ethiopia. Soil and Tillage Research 94: 101-108. 
Bernard, E., Chenu, C., Balesdent, J., Puget, P. and Arrouaya, D. 1996. Fate of particulate organic matter in soil aggregates during cultivation. European Journal of Soil Science 47: 95-503.

Black, C.A. 1965. Methods of Soil Analysis. Part.1. American Society of Agronomy, USA. 770p.

Blair, J.M., Parmelee, R.W. and Lavelle, P. 1995. Influences of earthworms on biogeochemistry. In: Hendrix, P.F. (Ed.), Earthworm Ecology and Biogeography in North America. CRC Press, Boca Raton, 127-158.

Brady, N.C. and Weil, R.R. 2008. The Nature and Properties of Soil. 14 ed. Prentice-Hall, Upper Saddle River, New Jersey.

Chan, K.Y., Bowman, A. and Oates, A. 2001. Oxidizidable organic carbon fractions and soil quality changes in an Oxic Paleustalf under different pasture. Soil Science 166: 61- 67.

Envis Centre Kerala. 2018. Environmental Information System, Kerala Council for Science Technology and Environment (KSCSTE), Ministry of Environment and Development, Thiruvananthapuram, pp. 84-98.

Filho, C.C., Lourenco, A., Guimaraes,F.M. and Fonseca, I.C.B. 2002. Aggregate stability under different soil management systems in a red latosol in the state of Parana, Brazil. Soil Tillage Research 651: 45-51.

Garten, C.T. 2011. Comparison of forest soil carbon dynamics at five sites along a latitudinal gradient. Geoderma 167(68): 30-40.

Gupta, R.K. and Rao, D.L.N. 1994. Potential of wastelands for sequestering carbon by reforestation. Current Science 66: $378-380$.

Hassink, J. 1994. Effects of soil texture and grassland management onsoil organic $\mathrm{C}$ and $\mathrm{N}$ and rates of $\mathrm{C}$ and $\mathrm{N}$ mineralization. Soil Biology and Biochemistry 26: 1221-1231.

Haynes, R.J. 2005. Labile organic matter fractions as central components of the quality of agricultural soils: An overview. Advances in Agronomy 85: 221-268.

Hoyle, F.C., Murphy, D.V. and Fillery, I.R. 2006. Temperature and stubble management influence microbial $\mathrm{CO}_{2}-\mathrm{C}$ evolution and gross $\mathrm{N}$ transformation rates. Soil Biology and Biochemistry 38: 71-80.

Huang, L., Wang C. Y., Tan, W. F., Hu, H. Q., Chong, F. C. and Ming, K.W. 2010. Distribution of organic matter in aggregates of eroded Ultisols, Central China. Soil and Tillage Research 108: 59-67.

Jenkinson, D.S. 1977. Studies on the decomposition of plant materials in soil. Journal of Soil Science 28: 424-434.

Jia, J., Yu, D., Zhou, W., Zhou, L., Bao, Y. and Meng, Y. 2015. Variations of soil aggregates and soil organic carbon mineralization across forest types on the northern slope of Changbai Mountain. Acta Ecologica Sinica 35(2): 1-7.
Kihara, J.A., Bationo, D.N., Mugendi, C., Martius, C. and Vlek, P.L.G. 2011. Conservation tillage, local organic resources and nitrogen fertilizer combinations affect maize productivity, soil structure and nutrient balances in semi-arid Kenya. Nutrient Cycling in Agroecosystems 90(2): 213-225.

Krishnakumar, A.K. and Potty, S.N. 1992. Nutrition of Hevea. In: Natural Rubber, Biology, Cultivation and Technology, (Eds.) M.R., Sethuraj and N.M., Mathew, Elsevier, New York pp. 199-228.

Krishnakumar. V. and Potty S.N. 2003. Nutrition of cardamom. In: Cardamom - The Genus Elettaria (Eds.) Ravindran P. N. and Madhusoodanan, K.J. pp. 145-148.

Lakaria, B.L., Mukherjee, A., Jha, P. and Biswas, A.K. 2012. Soil carbon mineralization as affected by land use systems and water regimes. Journal of the Indian Society of Soil Science 60: 71-73.

Liu, Z.X., Chen, X.M., Jing, Y., Li, Q.X., Zhang, J.B. and Huang Q.R. 2014. Effects of biochar amendment on rapeseed and sweet potato yields and water stable aggregate in upland red soil. Catena 123: 45-51.

Mazurak, A. P. 1950. Effect of gaseous phase on water-stable synthetic aggregates. Soil Science 69: 135-148.

Messiga, A.J., Ziadi, N., Angers, D. and Parent, L,E. 2011. Tillage practices of a clay loam soil affect soil aggregation and associated $\mathrm{C}$ and $\mathrm{P}$ concentrations. Geoderma 164(3):225-231.

McKenzie, N.J., Jacquier, D.J., Isbell, R.F. and Brown, K.L. 2004. Australian Soils and Landscapes: An Illustrated Compendium. CSIRO Publishing: Collingwood, Victoria.

Ping, C.L., Jastrow, J.D., Jorgenson, M.T., Michaelson, G.J., and Shur, Y.L. 2015. Permafrost soils and carbon cycling. Soil 1: 147-171.

Philip, A. and Abraham, J. 2016. Organic matter quality and carbon mineralization in humid tropical ultisol under rubber. Rubber Science 29(3): 256-263.

Post, W.M. and Kwon, K.C. 2000. Soil carbon sequestration and land-change: Processes and potential. Global Change Biology 6: 317-327.

Rahman, M.M. 2013. Carbon dioxide emission from soil. Agricultural Research 2(2): 132-139.

Schwendenmann, L., Pendall, E. and Potvin C. 2007. Surface soil organic carbon pools, mineralization and $\mathrm{CO}_{2}$ efflux rates under different land-use types in Central Panama. In: Stability of Tropical Rainforest Margins, (Eds) Tscharntke, C. Leuschner, M. Zeller, Guhardja E. and Bidin, A. Environmental Science and Engineering (Environmental Science), Springer, Berlin, Heidelberg.

Shi, H. J., Wang, X.J., Zhao, Y.J., Xu, M.G., Li, D.W. and Guo, Y. 2017. Relationship between soil inorganic carbon 
and organic carbon in the wheat-maize cropland of the North China Plain. Plant and Soil 418: 423-436.

Tisdall, J.M. and Oades, J.M. 1982. Organic matter and waterstable aggregates in soils. European Journal of Soil Science 33: 141-163.

Vieira, S.A., Alves, L.F., Duarte-Neto, P.J., Martinsm, S.C., Veiga, L.G., and Scaranello, M.A. 2011. Stocks of carbon and nitrogen and partitioning between above-and belowground pools in the Brazilian coastal Atlantic Forest elevation range. Ecology and Evolution 1(3): 421-434, doi: 10.1002/ece3.41.

Walter, K., Don, A., Tiemeyer, B. and Freibauer, A. 2016. Determining soil bulk density for carbon stock calculations: A systematic method comparison. Soil Science Society of America Journal 80(3): 579-591.

Wang, S.J., Ruan, H.H. and Han, Y. 2010. Effects of microclimate, litter type, and mesh size on leaf litter decomposition along an elevation gradient in the Wuyi Mountains, China. Ecological Research 25(6): 1113-1120.
Doi: 10.1007/s11284-010-0736-9 WOS: 000284422200007.

Xiang, C.H., Zhang, L. and Wen, D. 2015. Change of soil carbon fractions and water-stable aggregates in a forest ecosystem succession in south China. Forests 6: 2703-2718, doi:10.3390/f6082703.

Yoder, R.E. 1936. A direct method of aggregate analysis of soils and a study of the physical nature of erosion losses. Journal of American Society of Agronomy 28: 337-351.

Zhu, R., Zheng, Z., Li, T., Zhang, X., He, S. and Wang, Y. 2017. Dynamics of soil organic carbon mineralization in tea plantations converted from farmland at Western Sichuan, China, PLoS ONE 12(9): e0185271. https:// doi.org/10.1371/ journal.pone.0185271.

Zomer, R.J., Neufeldt, H., Xu, J., Ahrends, A., Bossio, D. Trabucco, A., van Noordwijk, M. and Wang, M. 2016. Global tree cover and biomass carbon on agricultural land: The contribution of agroforestry to global and national carbon budgets. Science Reporter 6: 29987; doi: 10.1038/srep29987. 